Review Article

\title{
Epidemiology of malaria as it relates to utilization of insecticide treated nets among pregnant women and under five years children in South-South Nigeria
}

\author{
Joseph O. Odoko ${ }^{1 *}$, Ezekiel U. Nwose ${ }^{2}$, Samuel D. Nwajei ${ }^{1}$, Emmanuel A. Agege ${ }^{1}$, \\ John E. Moyegbone ${ }^{1}$, Eunice O. Igumbor ${ }^{1}$
}

\author{
Received: 19 June 2020 \\ Revised: 06 August 2020 \\ Accepted: 09 September 2020 \\ *Correspondence: \\ Dr. Joseph O. Odoko, \\ E-mail: odokojosy@gmail.com
}

${ }^{1}$ Department of Public and Community Health, Novena University, Ogume, Nigeria

${ }^{2}$ School of Community Health, Charles Sturt University, Orange, NSW Australia

Copyright: (c) the author(s), publisher and licensee Medip Academy. This is an open-access article distributed under the terms of the Creative Commons Attribution Non-Commercial License, which permits unrestricted non-commercial use, distribution, and reproduction in any medium, provided the original work is properly cited.

\begin{abstract}
Pregnant mothers and children under five years are exposed to malaria infection. One of the WHO recommendations on prevention of malaria is the use of insecticide treated nets (ITNs). The use of ITNs is still low in Nigeria. Is to access challenges and improvement on use of ITNs among pregnant mothers and care givers of children under five in Bayelsa, Delta and Rivers state respectively. Review of articles related to use of ITNs among pregnant mothers and under five years children were adopted using The American Journal of Human Genetics among 28 studies. Malaria is responsible for $30 \%$ childhood and $11 \%$ maternal mortality despite the availability on use of ITNs. ITNs were $62.8 \%$ effective in reducing febrile episodes and $84.1 \%$ effective in reducing marked levels of malaria parasitemia. Mass distribution of bed-nets has increase ownership of ITNs resulting to $81.5 \%$ in Nigeria. Free ITNs has resulted in universal household ownership but the use of the nets is still very low in Nigeria. Malaria interventions are threatened by pyrethroids used in all ITNs. Irritation and suffocation are challenges to utilization of ITNs. In health promotion on use of ITNs, manufacturers' improvement on quality of ITNs is an epidemiological factor that could enhance the use among the vulnerable groups.
\end{abstract}

Keywords: Malaria epidemic, Global reports, ITNs, Mass distribution, Ownership, Utilization

\section{INTRODUCTION}

The world success on malaria elimination has been reported to be slowed compared to initial progress. ${ }^{1}$ There was no much difference of global malaria cases between 2010 to 2018 despite malaria intervention availability. ${ }^{2}$ This is especially in Africa, and Nigeria in particular where it is a major public health problem. ${ }^{3,4}$ Among the vulnerable population to malaria infection are pregnant women and children under 5-years. These are the subpopulation groups who are exposed to malaria related anemia that highly contributes to death if effective intervention is not taken. ${ }^{5}$
The 2016 report indicate that $99 \%$ of malaria cases in sub-Saharan Africa are caused by Plasmodium falciparum, $P$. vivax is the common parasite. ${ }^{6}$ WHO recommends use of long-lasting ITNs (LLINs); intermittent preventive treatment in pregnancy (IPTp) with sulfadoxine-pyrimethamine (SP) and prompt diagnosis as well as effective treatment among pregnant women during antenatal care services. ${ }^{7}$ Yet, malaria interventions are threatened by resistance of malaria vectors to pyrethroids used in all ITNs, which has been on the increase from between 2010 and $2016 .{ }^{8}$ It is agreed that to achieve universal ITN coverage, affected countries with malaria infections need to subscribe to supportive 
program to reach global malaria targets for 2020 and beyond (Figure 1). ${ }^{6}$

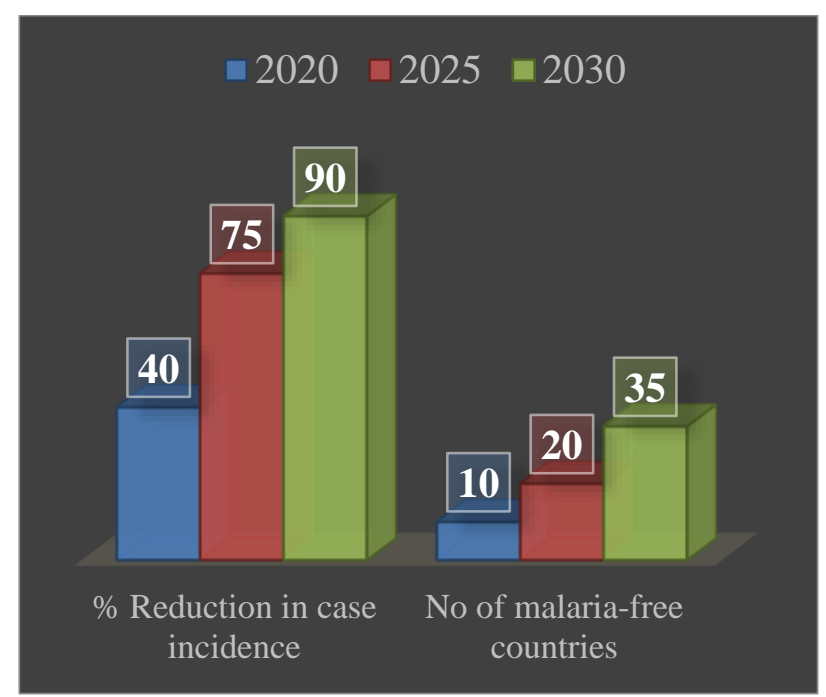

Figure 1: Global malaria target for $2020-2030$ relative to 2015 .

Adapted from 'The E-2020 initiative of 21 malaria-eliminating countries: 2019 progress report' ${ }^{8}$

There has been decline in malaria infection in Africa due to increase investment to eliminate malaria but sustaining it has been a difficult issue for indigenous malaria cases in African countries. 9 WHO recommend one ITN for every two people at risk of malaria; hence Nigeria has been involved in free mass distribution of LLINs to vulnerable populations. ${ }^{3}$ The renewed target for roll back malaria (RBM) in Nigeria now includes to control malaria with targeted key performance indices including

- $80.0 \%$ of children <5years and pregnant women to use ITN. ${ }^{10}$

- $74 \%$ of ownership of ITNs in households through mass distribution. ${ }^{11}$

Despite the evidence that the use of ITNs decreases malaria related mortality and morbidity, its use is still low as reported by the 2013 Demographic Health survey in Nigeria. ${ }^{4}$ There is evidence that ITNs coverage or ownership seems to have achieved the RBM target. However, utilization is quite low and a far cry as most of the owners are not utilizing their nets due to various factors. ${ }^{12}$ A study to identify factors that are meant to be eliminated for effective utilization of ITNs among pregnant mothers and care givers of under five years children in Bayelsa State, Delta State and Rivers State within South-South Nigeria will go a long way to influence stake holders in promoting the health of the vulnerable population against malaria infection.

\section{GLOBAL MALARIA CASES AND MORTALITY}

Global report on malaria in 2015 indicates that malaria infections were about 212 million cases and had caused
429,100 deaths. Majority of the affected populations are more of children and pregnant mothers. ${ }^{13}$ In 2016, 91 countries experienced 216 million malaria cases, with 5 million cases higher than the previous year. The mortality rate due to malaria was recorded at 445, 000 deaths which was similar to figures reported in $2015 .^{6}$ These indices show that the global burden of malaria did not seem to be a continuous or consistent declining trend in the past decade. Indeed, the 2017 data appear worse than 2015 (Figure 2). ${ }^{5}$ It is acknowledged that cases of malaria reduced globally between 2010 and 2018 from 71 to 57 cases per 1000 population at risk. That of 2014 to 2018 which was 57 cases $85 \%$ higher among 20 countries in Africa Region and India. ${ }^{7,8}$

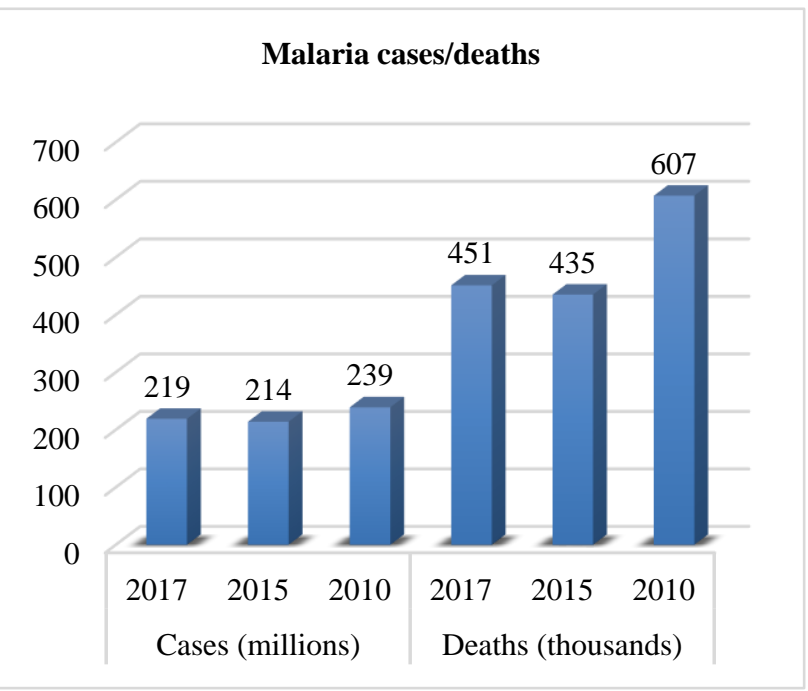

Figure 2: Numbers of malaria cases and deaths at baseline, 2015 vs. 2017.

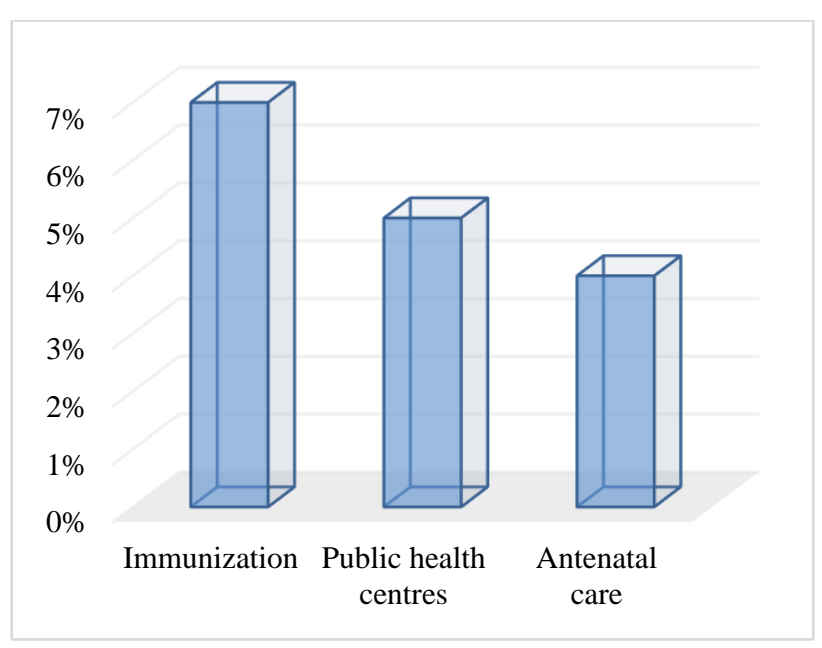

Figure 3: Increase in ITN distribution by healthcare venue.

\section{Prevention of malaria with use of ITNs}

WHO recommends use of LLINs, IPTp and SP as well as prompt diagnosis and effective treatment of malaria 
infections as main stay among pregnant women during antenatal care services. ${ }^{7}$ In 2016 intervention against malaria infection with the use of ITNs shows that $54 \%$ of people at risk of malaria in sub-Saharan Africa were sleeping under it. This ITNs utilization rate is not near the goal of universal access. ${ }^{6}$ Between 2016 and 2018, 578 million ITNs were distributed by producers worldwide, out of which $50 \%$ went to Africa and India. The African countries include Côte d'Ivoire, Democratic Republic of Congo, Ethiopia, Ghana, Nigeria, Uganda and the United Republic of Tanzania. Globally, $80 \%$ of ITNs were distributed through mass distribution campaigns, $10 \%$ in antenatal care facilities and $6 \%$ as part of immunization programs (Figure 3$){ }^{8}$

\section{Challenges in progress of malaria control as it concerns ITNS}

Lack of sustainable and predictable international and domestic funding, humanitarian crisis in malaria endemic territories, poor climate conditions, emergence of parasite resistance to antimalarial treatment and mosquito resistance to insecticides are noticed in some countries. ${ }^{6}$ Malaria intervention are threatened by resistance of malaria vectors to pyrethroids used in all ITNs, which has been on the increase from between 2010 and $2016 .{ }^{8}$ Irrespective of the slow progress in elimination of malaria, there is hope of progress and lessons to be learnt in countries. For instance, Algeria in Africa is among the few countries that have reported zero indigenous cases for a minimum of two consecutive years (Figure 4), and are certificated malaria free. ${ }^{5}$

\section{Countries}

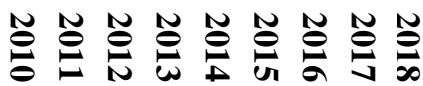

\author{
Paraguay \\ (America) \\ Algeria (Africa) \\ El Salvador \\ (America) \\ China (Western \\ Pacific)
}

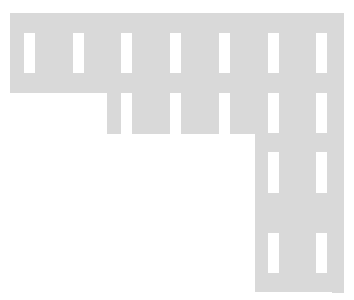

Figure 4: Countries that have achieved malaria-free status in $\geq 2$ years.

Adapted from 'The E-2020 initiative of 21 malaria-eliminating countries: 2019 progress report'.

\section{AFRICA: SUB-SAHARAN MALARIA CASES AND MORTALITY}

So much can be said of malaria in Africa e.g. 15 countries in Sub-Saharan Africa responsible for about $80 \%$ of the world malaria infection. ${ }^{3}$ Malaria has been identified for decades as a public health problem in Sub-Saharan Africa. It has caused a high rate of and death among women of child bearing age and children under one year old in Africa. One of the five highest deadly diseases in
Sub-Saharan Africa is malaria. ${ }^{14}$ According to the WHO 2017, there were 216 million cases of malaria in the world and 445,000 deaths took place in 2016 of which $90 \%$ of the deaths occurred in Africa continent and $80 \%$ of the reported case is from Sub-Saharan Africa. All ages and sexes are affected by malaria, although low immunity level among pregnant mothers and under five years children has been an underlining factor responsible for high rates of death. ${ }^{15}$ Plasmodium falciparum is the most highly rated parasite over $\mathrm{P}$. vivax that causes malaria infection in Africa. In fact, WHO reported that

- In every 50 seconds, a child dies of malaria hence a constraint to socio-economic development. ${ }^{16}$

- Malaria is wide spread among 76 countries in Africa and Asia. ${ }^{8,17}$

- In the 2019 global malaria report,19 countries in subSaharan Africa and India contributed $85 \%$ of the global burden. In other perspectives, Africa contributed $93 \%$ (Table 1); while Nigeria is one of 6countries that accounted for $54 \%$ of all malaria cases (Figure 5). ${ }^{7}$

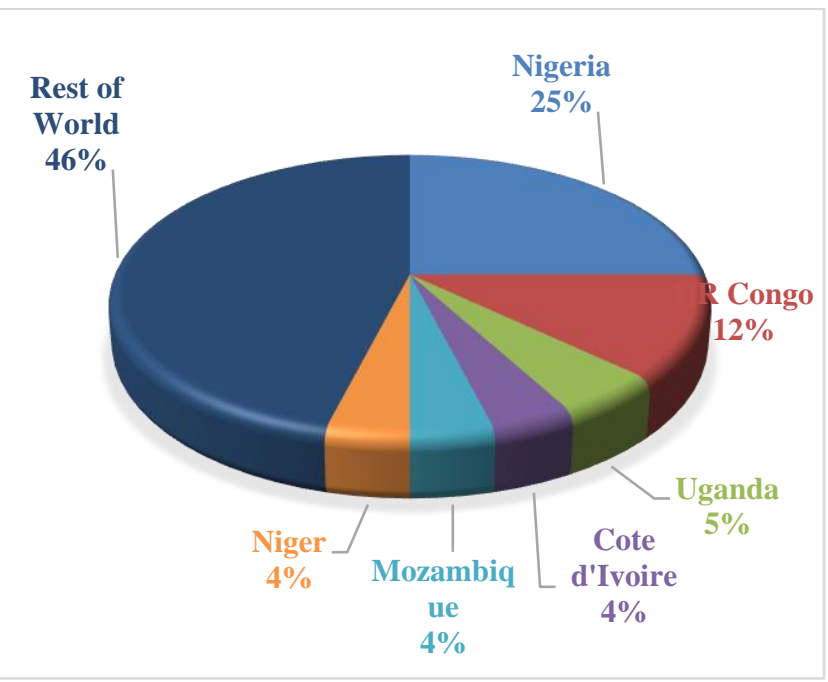

Figure 5: Nigeria as most affected global cases.

Table 1: Global malaria cases according to WHO report of 2019.

\begin{tabular}{|c|c|c|}
\hline Year & $\begin{array}{l}\text { Estimated } \\
\text { cases (millions) }\end{array}$ & $95 \% \mathrm{CI}$ \\
\hline \multicolumn{3}{|l|}{ Estimates } \\
\hline 2010 & 251 & $231-278$ \\
\hline 2017 & 231 & $211-259$ \\
\hline 2018 & 228 & $206-258$ \\
\hline \multicolumn{3}{|c|}{$\begin{array}{l}\text { Distribution of occurrence of malaria-2018 cases } \\
(\%)\end{array}$} \\
\hline African region & 93.0 & \\
\hline South-East Asia & 3.4 & \\
\hline Eastern Mediterranean & 2.1 & \\
\hline Rest of World & 1.5 & \\
\hline Total & 100.0 & \\
\hline
\end{tabular}




\section{Policy on malaria prevention with the use of ITNs in Africa}

WHO in 1992 emphasize that ITNs is the best and reliable preventive strategy against malaria burden. Ghana as a signatory to the May 2006 Abuja Declaration. As part of the objective of the RBM, agenda was to raise ITNs ownership to $80 \%$ and utilization to $60 \%$ by 2010 . Further target set for 2015 was to achieve $100 \%$ ownership and $80 \%$ usage. $^{14}$

The WHO recommends utilization of ITNs as the main strategy towards control of malaria by all ages and sexes. Distribution of free ITNs should be the main intervention in national malaria control strategy in all Sub-African countries. WHO target of $85 \%$ coverage is a vital key performance index to distribution of ITNs supply. Adjunct to this recommendation is one ITN for every two people who are at risk of malaria. ${ }^{3}$ The Abuja declaration in 2000 by African leaders for the provision of $60 \%$ of ITNs for African children by 2005 is yet to be achieved by Sub-Saharan countries, despite their effort to meet universal coverage. ${ }^{18}$ Most countries are below the set target of protection coverage. ${ }^{16}$

\section{Constraints and achievements in Malaria Control with the use of ITNs in Africa}

Funding of malaria programs by donors has been scarce in Sub-Saharan African countries. Thus, making the fight against malaria a difficult task. Poor awareness or knowledge about malaria preventive measures, and misunderstanding between couples on use of ITNs is reported in previous investigations. ${ }^{19}$ Factors identified as challenges for ownership ITNs include, but not limited to: ${ }^{16}$

- Awareness or knowledge: level of understanding on use of bed nets,

- Demographic factors: age, sexes, marital status, and occupation

- Access to healthcare: distance to nearest antenatal care,

- Affordances: access and cost including availability of transport as well as house-hold size

Studies from Africa reveal that ownership of bed nets cannot be interpreted as utilization of the ITNs. The latter makes it far from meeting the target of universal coverage. Utilization of ITNs has been reported to be as low as $9.6 \%$. Reasons for non-utilization of ITNs in Africa are perceived un-comfortability and hotness created by ITNs, low understanding of malaria prevention. Inadequate separate sleeping rooms, poor quality of ITNs and inadequate ITNs to the house hold members. ${ }^{14}$

The issue of poor quality underpins failure rates. Reemergence of malaria has been experienced in Senegal, Western Kenya, Gambia, Benin, Tanzania and Uganda where ITNs have been utilized. These situations warrants the need to study the main challenge of resistance to ITNs of the mosquitoes that causes malaria. ${ }^{20}$ In Sub-Saharan Africa, it is estimated that the population of users of ITNs have gone up from less than $2 \%$ in 2000 to $67 \%$ in 2015 . Modification of nets into pyrethroid treated bed nets has help to reduce vector increase, number of infection rates in Anopheles populations leading to decline in malariaassociated cases and death rates in African countries. ${ }^{20}$

However, the study in Benin, Equatorial Guinea and Malawi have shown that distribution and utilization of new ITNs provide more advantages to reduce malaria burden despite pyrethroid ITNs resistance than use of old ITNs. $^{21}$ Therefore, it must be acknowledged that regardless of poor quality, ownership and utilization of the available ITNs is a sine qua non.

\section{NIGERIA: MALARIA CASES AND MORTALITY}

\section{Epidemiology on utilization of ITNs among pregnant mothers and under five children in Nigeria}

Nigeria is among 11 countries that account for $70 \%$ in the world malaria deaths rate. ${ }^{22}$ Malaria is a major public health problem in Nigeria and it is responsible for $30 \%$ childhood and $11 \%$ maternal mortality, despite the availability of effective interventions. ${ }^{4} 100 \%$ of the Nigerian populations are at risk of malaria infection. Nationally, the malaria burden accounts for $60 \%$ of outpatient visits to health facilities. ${ }^{23}$ Malaria infection is endemic in Nigeria, and everybody is at risk with a prevalence of 919 per 10,000 (9\%) of population. ${ }^{10}$ Nigeria leads other ten African countries with a high burden of malaria and accounted for $25 \%$ of total malaria cases (Figure 5), and $19 \%$ of malaria deaths worldwide in $2017 .^{24}$

According to the statistics of the Nigerian National Malaria Control program, the burden of malaria includes $60 \%$ of outpatient visits to health facilities (Figure 6); and an estimated annual loss of 132 billion Naira in the form of treatment and prevention costs, and loss of man-hours, amongst other losses. ${ }^{25}$ The geographic spread of the malaria burden is heterogeneous in the country, with the highest prevalence among children ages 6 to 59 months in the North Central, North East and North West regions, and the lowest prevalence in the South East region. ${ }^{23}$

\section{Policy of malaria prevention on use of ITNs in Nigeria}

The Government of Nigeria, through the National Malaria Elimination Programme (NMEP) and in collaboration with partners, is scaling up malaria prevention and treatment interventions in line with the goals of the National Malaria Strategic Plan (NMSP) 2014-2020. NMEP employs a mixed-model approach for ITN distribution that includes free mass distribution campaigns and continuous distribution of ITNs to supplement the mass campaigns. Continuous distribution relies on several routine health service delivery channels: 
immunization campaigns; antenatal care (ANC); the integrated maternal, newborn, and child health week; school-based distribution; community-based distribution; and, distribution through the commercial sector. ${ }^{23}$ as previously indicated in the narrative (Figure 3), the majority of households receive free ITNs from different venues and through mass distribution campaigns. ${ }^{23}$

For instance, the Rivers State government of Nigeria has distributed more than two million nets, during the Immunization Plus days, and stand-alone campaigns, in its effort to meet the target of providing two ITNS per household in the State. Although, the usage of the nets is still very poor. ${ }^{25}$ Another report indicates high proportion of households in two other states $(87 \%$ in Bauchi and $72 \%$ in Cross River) had at least one ITN during mass distribution between 2010 and 2011. ${ }^{26}$

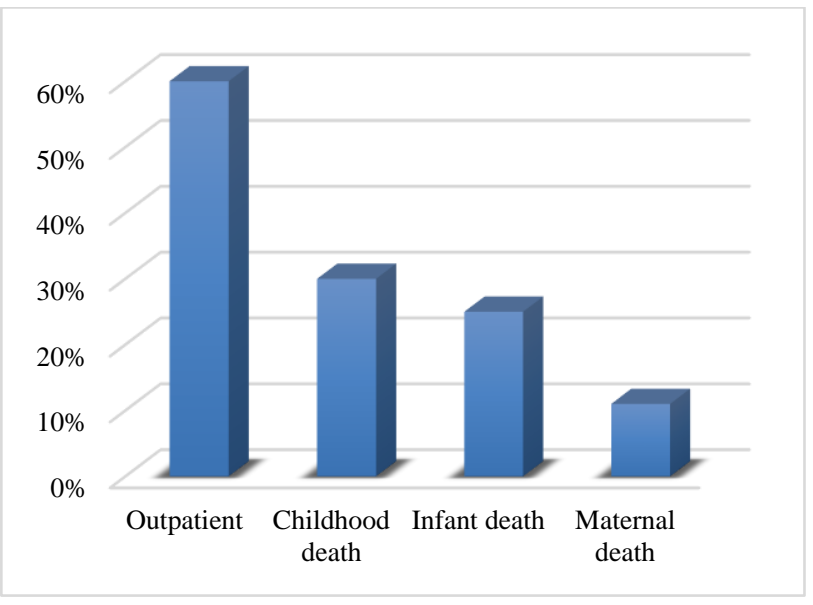

Figure 6. Statistics of malaria burden in Nigeria. ${ }^{25}$

\section{Challenges in malaria control with the use of ITNs in Nigeria}

Despite the common occurrence of malaria during pregnancy, there was a limited knowledge and use of recommended anti-malarial intervention by women attending antenatal clinics. Many pregnant women who due to poverty and/or lack of education do not go for antenatal care and have no access to preventive malaria care. These categories of women may present when the disease is severe. Inconsistent and/or inappropriate use of bed-nets has been reported to be a challenge. ${ }^{4}$ In Rivers State, it was discovered that a large proportion of the nets were not used over beds and mattresses, but as screens for windows and doors; probably to escape the discomfort from heat that is a common complaint amongst users of the net. ${ }^{25}$

Further, the more disadvantaged households were less likely to have a ITN, ${ }^{26}$ and only one-third of those who owned bed-nets slept under the net during the night preceding the survey, thus, highlighting the alarming gap between net ownership and utilization. The most common reason, given for not using the nets was suffocation or hot condition due to lack of proper air circulation in the net. This has largely been attributed to the hot tropical climate of the sub-Saharan African region and agrees with findings from other studies done in different African countries where low bed net utilization has been reported. $^{27}$

\section{Expectation of progress in malaria control with use of ITNS}

The efficacy and cost effectiveness of ITN in reducing malaria has led to free or highly subsidized ITN to pregnant women and under five children. Following the recommendation by the WHO, the ITNs distributed by the National Malaria Elimination Programme have been LLIN brands. Household ownership of at least one LLIN in Nigeria increased from $44 \%$ in 2010 to $69 \%$ in 2015. This was the result of routine and periodic mass distribution for rapid scale-up of LLINs in the communities. $^{24}$ ITNs coverage or ownership seems to have achieved the RBM target.

Reports have indicated that sleeping regularly under ITNs is the most effective way to prevent malaria among children and that ITN was $62.8 \%$ success in reducing febrile episodes, but more effective in reducing marked levels of malaria parasitaemia. ${ }^{10}$

However, utilization is quite low and a far cry as most of the owners are not utilizing their nets. Previous study report shows that patient experience of discomfort, heat, irritation and suffocation limits utilization, while affordances and quality are further barriers to utilization. It behooves on ITNs manufactures to improve the quality of nets, while healthcare workers and government agencies vigorously increase the campaign of creating more awareness on how best to use the ITNs among pregnant mothers. ${ }^{12}$

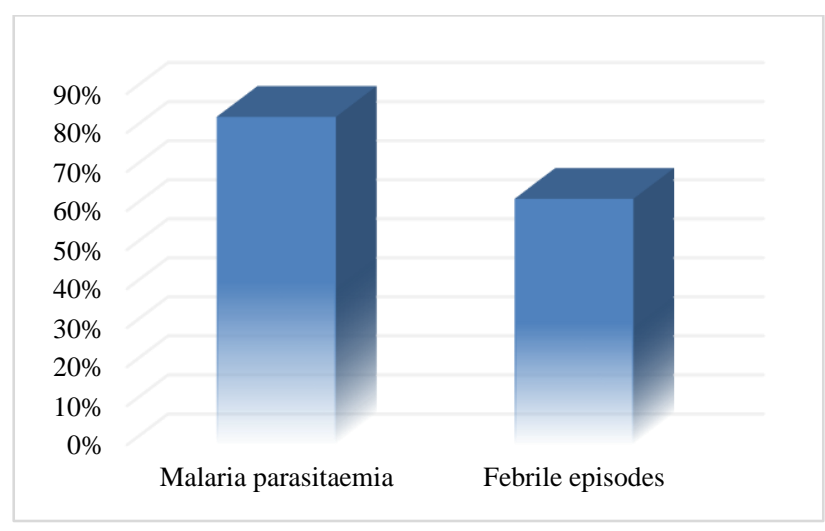

Figure 7: Effectiveness of ITNs in reducing febrile episode vs mal parasitaemia. ${ }^{10}$

\section{DISCUSSION}

The objective of this epidemiological narrative review is to articulate what is known regarding challenges and 
necessary improvement on use of ITNs among pregnant mothers and care givers of children. The main aim of developing strategies to prevent malaria infection is because of evidence of high rate of malaria cases and mortality in the world. Global malaria data released in 2019 indicate public health epidemiology that requires concerted and enhanced effort to improve the situation, especially in Nigeria that contributes a quarter of the world's burden. This is regardless of global report indicating that progress in controlling malaria infection has been stalled. ${ }^{28}$

Identified slow progress on malaria elimination is due to factors such as poor funding in investment of malaria control by many donor countries and agencies, emerging of resistance to malaria commodities such as pyrethroid ITNs by malaria vectors, poor attitude to effective utilization of insecticide nets by owners of bed nets, inadequate distribution of nets to vulnerable groups such as pregnant mothers and children under five years. World Health Organization best recommended strategy for prevention of malaria is adoption of use of LLINs, and two doses of SP for pregnant mothers and children under five years.

Universal coverage on use of ITNs has been low due to poor utilization by those who owns the nets encouraging increase of malaria infection. Poor use of ITNSs increases incidences of malaria episode, maternal and fetal anemia, placental parasitemia, low birth weight and neonatal mortality. Therefore, various State government should contribute immensely for continuous distribution of ITNs at various household and rigorous health education on utilization to be the watch guide to health workers. This translates to potential health promotion strategy of monitoring pregnant mothers as well as care-givers to change their attitude in the use of LLINs. By further interpretation, antenatal clinics and immunization sites constitute one of the avenues for such health promotion vis-à-vis educational campaign.

\section{CONCLUSION}

As a result of various factors that have been a hindrance to effective utilization of ITNs, WHO and regional leaders should sustain the policy of free distribution of nets to households. Perhaps, lessons need to also be learnt from countries like Algeria and Paraguay that have achieved malaria-free status. While manufacturers need to improve on the quality of their products, monitoring of utilization of the distributed nets is a sine qua non to progress towards malaria-free target.

\section{ACKNOWLEDGEMENTS}

Author acknowledged all staff and research scholars of department of public and community health, Novena University, Ogume, Delta State as well as the Provost and colleagues at Bayelsa State College of Health Technology for their contributions towards the success of this work.
Funding: No funding sources Conflict of interest: None declared Ethical approval: Not required

\section{REFERENCES}

1. World Health Organization. World Malaria Day 2018: Ready to beat malaria. Retrieved from https://www.who.int/campaigns/malariaday/2018/event/en/. Accessed on 18/06/2020.

2. World Health Organization. The "World malaria report 2019" at a glance. Retrieved from https://www.who.int/news-room/featurestories/detail/world-malaria-report-2019. Accessed on 18 June 2020.

3. Olapeju B, Choiriyyah I, Lynch M, Acosta A, Blaufuss S, Filemyr E et al. Age and gender trends in insecticide-treated net use in sub-Saharan Africa: a multi-country analysis. Malar J. 2018;17:423.

4. Titiloye MA, Onuosa EA and Arulogun OS. Malaria prevention practices among pregnant women resident in two Nigeria army barracks, Ibadan, South Western, Nigeria. J Pub Health Epidemiol. 2017;9:920-98.

5. World Health Organization. World malaria report 2017. Available at: https://endmalaria.org/sites/ default/files/9789241565523-eng.pdf. Accessed on 18/06/2020.

6. World Health Organization. World malaria report 2018. Available at: https://www.who.int/ malaria/publications/world-malaria-report-2018/en/. Accessed on 18/06/2020.

7. Fried M, Duffy PE. Malaria during pregnancy. Cold Spring Harb Perspect Med. 2017;7:025551.

8. World Health Organization. The E-2020 initiative of 21 malaria-eliminating countries: 2019 progress report. Available at: https://apps.who.int/iris/ bitstream/handle/10665/325304/WHO-CDS-GMP2019.07-eng.pdf?ua=1. Accessed on 18/06/2020.

9. Dhiman S. Are malaria elimination efforts on right track? An analysis of gains achieved and challenges ahead. Infect Dis Poverty. 2019;8:14.

10. Orji ML, Onyire NB, Chapp-Jumbo A, Anyanwu OU, Eke CB. Perception and utilization of insecticide-treated mosquito net among caregivers of children in Abakaliki, Nigeria. Ann Afr Med. 2018;17:172-7.

11. National Population Commission - NPC Nigeria and ICF. Nigeria Demographic and Health Survey 2018. Retrieved

from https://dhsprogram.com/pubs/pdf/FR359/FR359.pdf. Accessed on 18/06/2020.

12. Odoko JO, Nwose EU, Igumbor EO. Evaluation of utilization of insecticide treated nets among pregnant women in Bayelsa State of Nigeria: a case study of Sagbama community. Int J Res Med Sci. 2018;6:2571-7.

13. World Health Organization. World malaria report 2016. Available at: https://apps.who.int/iris/ 
bitstream/handle/10665/252038/9789241511711eng.pdf?sequence=1. Accessed 12 June 2020.

14. Nyavor KD, Kweku M, Agbemafle I, Takramah W, Norman I, Tarkang E, et al. Assessing the ownership, usage and knowledge of Insecticide Treated Nets (ITNs) in Malaria Prevention in the Hohoe Municipality, Ghana. Pan Afr Med J. 2017;28:67.

15. Yitayew AE, Enyew HD, Goshu YA. Utilization and Associated Factors of Insecticide Treated Bed Net among Pregnant Women Attending Antenatal Clinic of Addis Zemen Hospital, North-Western Ethiopia: An Institutional Based Study. Malar Res Treat. 2018; 2018: 3647184.

16. Fokam EB, Kindzeka GF, Ngimuh L, Dzi KTJ, Wanji S. Determination of the predictive factors of long-lasting insecticide-treated net ownership and utilisation in the Bamenda Health District of Cameroon. BMC Public Health. 2017;17:263.

17. Dambach P. New approaches for integrated and costeffective malaria vector control. J Rare Dis Res Treat. 2018;3:6-10.

18. Sexton AR. Best practices for an insecticide-treated bed net distribution programme in sub-Saharan eastern Africa. Malar J. 2011;10:157.

19. Yaya S, Uthman OA, Amouzou A, Bishwajit G. Use of intermittent preventive treatment among pregnant women in Sub-Saharan Africa: Evidence from Malaria Indicator Surveys. Trop Med Infect Dis. 2018;3.

20. Sougoufara S, Doucouré S, Backé Sembéne PMB, Harry M, Sokhna C. Challenges for malaria vector control in sub-Saharan Africa: Resistance and behavioral adaptations in Anopheles populations. J Vector Borne Dis. 2017;54:4-15.

21. Lindblade KA, Mwandama D, Mzilahowa T, Steinhardt L, Gimnig J, Shah M et al. A cohort study of the effectiveness of insecticide-treated bed nets to prevent malaria in an area of moderate pyrethroid resistance, Malawi. Malar J. 2015;14:31.

22. World Health Organization and RBM Partnership to End Malaria. High burden to high impact: a targeted malaria response. 2018; Retrieved from https://apps.who.int/iris/bitstream/handle/10665/2758 68/WHO-CDS-GMP-2018.25-eng.pdf?ua=1.

Accessed on 18 June 2020.

23. Andrada A, Herrera S, Inyang U, Mohammed AB, Uhomoibhi P, Yé, Y. A subnational profiling analysis reveals regional differences as the main predictor of ITN ownership and use in Nigeria. Malar J. 2019;18:185.

24. Babalola OJ, Sambo MN, Idris SH, Ajayi IOO, Ajumobi O, Nguku P. Factors associated with utilization of LLINs among women of child-bearing age in Igabi, Kaduna State, Nigeria. Malar J. 2019;18:412.

25. Ordinioha B. The use and misuse of mass distributed free insecticide-treated bed nets in a semi-urban community in Rivers State, Nigeria. Ann Afr Med. 2012;11:163-8.

26. Eteng M, Mitchell S, Garba L, Ana O, Liman M, Cockcroft A et al. Socio-economic determinants of ownership and use of treated bed nets in Nigeria: results from a cross-sectional study in Cross River and Bauchi States in 2011. Malar J. 2014;13:316.

27. Tobin-West CI, Alex-Hart BA. Insecticide - treated bednet ownership and utilization in Rivers State, Nigeria before a state-wide net distribution campaign. J Vector Borne Dis. 2011;48:133-7.

28. World Health Organization. Malaria in children under five. 2018; Available at: https://www.who.int/malaria/areas/high_risk_groups/ children/en/. Accessed on 18 June 2020.

Cite this article as: Odoko JO, Nwose EU, Nwajei $\mathrm{SD}$, Agege EA, Moyegbone JE, Igumbor EO. Epidemiology of malaria as it relates to utilization of insecticide treated nets among pregnant women and under five years children in South-South Nigeria. Int J Community Med Public Health 2020;7:4157-63. 